\title{
An Additional, Complementary Mechanism of Action for Folic Acid in the Treatment of Megaloblastic Anemia
}

\section{Bruce K Kowiatek*}

The Wellness Pharmacy, Winchester, Virginia, USA

*Corresponding Author: Bruce K Kowiatek, The Wellness Pharmacy, 110 Highpointe Court, Winchester, Virginia 22602, USA

Received: 13 November 2018; Accepted: 20 November 2018; Published: 22 November 2018

\begin{abstract}
Administration of supplemental folic acid addresses the impaired DNA synthesis causing megaloblastic anemia; however, despite the possibility of high doses of folic acid-5 to 15 milligrams (mg) daily for up to four months-the extremely rapid initial onset of action-30 to 60 minutes-when administered orally is not in keeping with the accepted mechanism, which can take up to nearly 22 hours, even under enzymatic control. This would suggest an additional, complementary non-enzymatic mechanism of nucleotide methylation at work; it is, therefore, proposed here, with in vitro evidence put forth, that rapid, non-enzymatic methylation by folic acid, via 5,10-methylenetetrahydrofolate and 7,8-tetrahydrofolate intermediates, of deoxyuridine monophosphate to form thymidylate using the cell membrane phospholipid phosphatidylcholine as a methyl donor, leaving de-methylated phosphatidylethanolamine, is a viable additional and complementary mechanism in helping reduce megaloblastic red blood cells to normal size and function.
\end{abstract}

Keywords: Folic acid; DNA; Megaloblastic anemia; Deoxyuridine monophosphate; Thymidylate

Abbreviations: DNA: deoxyribonucleic acid; DHFR: Dihydrofolate Reductase; NADH and NAD+: Nicotinamide Adenine Dinucleotide (reduced and oxidized forms, respectively); THF: Tetrahydrofolate

\section{Introduction}

Dietary deficiency of the vitamin enzyme cofactor folic acid (Figure 1) has serious effects upon human health, including chromosome breaks, birth defects such as neural tube defects, increased risk of colon cancer, brain dysfunction, and heart disease [1]. Its deficiency is also the cause of megaloblastic anemia, or megaloblastosis, an anemic blood disorder characterized by larger-than-normal red blood cells (RBCs), or megaloblasts [2]. Two 
hallmarks of megaloblasts are, first, elevated levels of the cell membrane phospholipid phosphatidylcholine (PC) [3] (Figure 2) and, second, increased amounts of the nucleotide deoxyuridine 5'-monophosphate (dUMP), which is otherwise usually methylated by the folic acid derivatives 5,10-methylenetetrahydrofolate and 7,8-dihydrofolate, via the thymidylate synthase enzyme pathway, which also includes the enzyme dihydrofolate reductase (DHFR), the coenzyme nicotinamide adenine dinucleotide in both its reduced and oxidized forms (NADH and NAD+, respectively), and the folic acid derivative tetrahydrofolate (THF), to deoxythymidine 5'-monophosphate (dTMP), or thymidylate, as part of normal deoxyribonucleic acid (DNA) synthesis [4] (Figure 3).

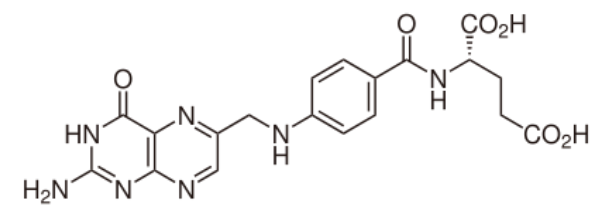

Figure 1: Folic acid.

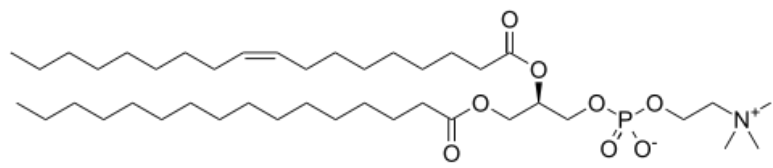

Figure 2: Phosphatidylcholine (PC).

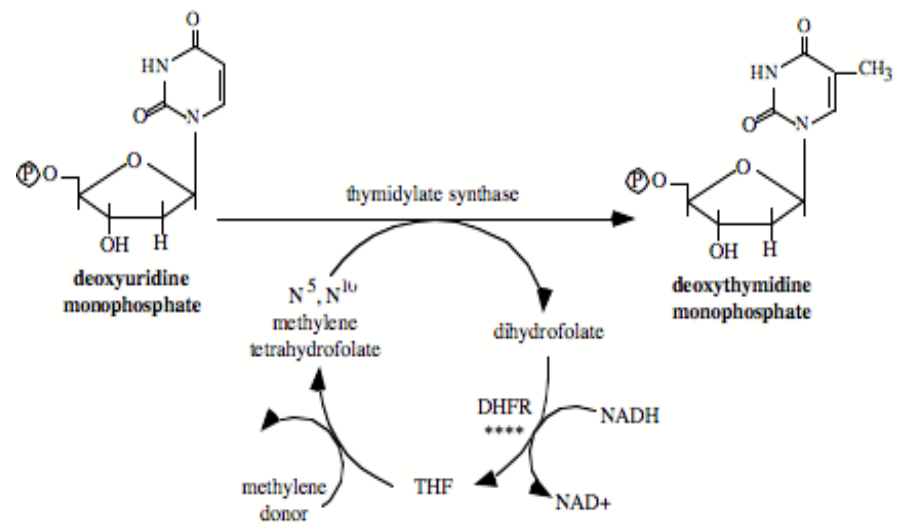

DHFR: Dihydrofolate Reductase; NADH and NAD+: Nicotinamide Adenine Dinucleotide (reduced and oxidized forms, respectively); THF: Tetrahydrofolate.

Figure 3: Thymidylate synthase pathway.

Administration of supplemental folic acid addresses the impaired DNA synthesis causing megaloblastosis; however, despite the possibility of high doses of folic acid-5 to 15 milligrams ( $\mathrm{mg}$ ) daily for up to four months-the extremely rapid initial onset of action-30 to 60 minutes-when administered orally [5] is not in keeping with this accepted mechanism, which can take up to nearly 22 hours, even under enzymatic control [6]. This would suggest an additional, complementary non-enzymatic mechanism of nucleotide methylation at work. Such non-enzymatic 
methylation of nucleotides has been observed previously in vitro with the metabolite cofactor S-adenosylmethionine (SAM-e) [7]; it is, therefore, proposed here, with in vitro evidence put forth, that rapid, non-enzymatic methylation by folic acid, via 5,10-methylenetetrahydofolate and 7,8-dihydrofolate intermediates, of dUMP to form thymidylate using PC as a methyl donor, leaving the de-methylated cell membrane phospholipid phosphatidylethanolamine (PE) (Figure 4), is a viable additional and complementary mechanism in helping reduce megalobastic RBCs to normal size and function.

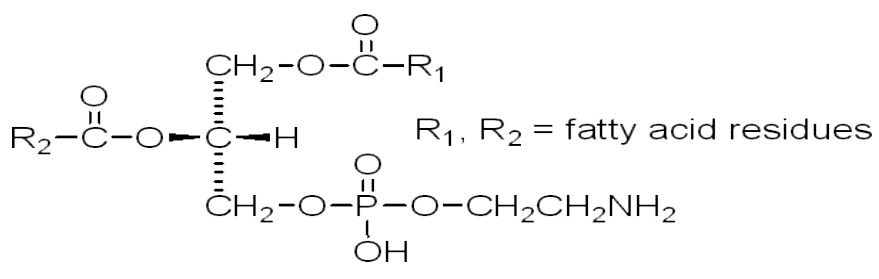

Figure 4: Phosphatidylethanolamine (PE).

\section{Experimental}

All research was conducted at The Wellness Pharmacy in Winchester, VA, USA from February of 2018 through March of 2018. All sterile manipulations were performed using aseptic technique [8] in a NUAIRE Biological Safety Cabinet Class II Type A/B3 laminar flow hood. All pH measurements were made using a Horiba TwinpH waterproof B-213 Compact pH Meter. All Gas Chromatography/Mass Spectrometry (GC/MS) data was obtained using a Hewlett Packard 5890 Series II Gas Chromatograph. Compounds were identified as the trimethylsilyl (TMS) derivatives by using the agreement of the retention times with those of standards as the criterion for identification and the following ions for determination: $\mathrm{m} / \mathrm{z} 321.0488$ for thymidylate [9], and m/z 255.13 for PE [10]. All inlaboratory photography was obtained using a Casio EX-Z57 digital camera. All Pyrex glassware was sterilized at $130^{\circ} \mathrm{C}$ for one hour [11] via autoclave using a Quincy Lab Inc. Model $30 \mathrm{GC}$ Lab Oven. All chemical supplies were purchased from the Professional Compounding Centers of America (PCCA) in Houston, TX, USA.

All measurements of chemicals were standardized to 0.1 Molarity (M) $\pm 5 \%$ using an Ohaus Analytical Plus electronic balance accurate to within \pm 0.0001 gram (g). Final test and control samples were obtained via filtration through a sterile 0.2 micron $(\mu \mathrm{m})$ EPS, Inc. Medi-Dose Group Disposable Disc Filter Unit and corresponding sterile Monoject syringe. Three trials per step were performed and recorded and the data presented here represents the average of that total data. All data collected fell within a statistically acceptable $\pm 5 \%(\mathrm{p}=0.05)$ internal margin of variance [12] with no outliers. As a control, 25 milliliters $(\mathrm{mL})$ of sterile $0.9 \%$ sodium chloride in water (normal saline (NS)), $\mathrm{pH} 7.4$, was heated to $37^{\circ} \mathrm{C}$ and maintained, with $0.45 \mathrm{~g}$ of PC (95\% $\left.\pm 5 \%\right)$ added and allowed to melt uniformly throughout (Figure 5). To this was added $0.015 \mathrm{~g}$ of folic acid (Figure 6) and the $\mathrm{pH}$ adjusted first downward to 2 via titration with $0.1 \mathrm{M}$ hydrochloric acid $(\mathrm{HCl})$, then upward to 10 via titration with $0.1 \mathrm{M}$ sodium hydroxide $(\mathrm{NaOH})$ solution. The $\mathrm{pH}$ was then adjusted back to 7.4 via $\mathrm{HCl}$. 


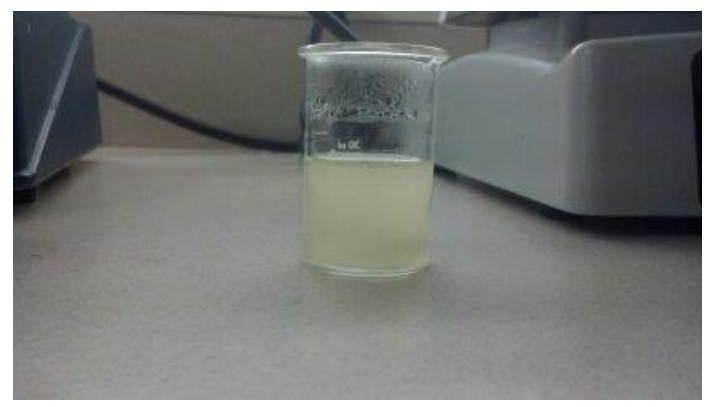

Figure 5: Control mixture of $25 \mathrm{~mL} \mathrm{NS}, \mathrm{pH} 7.4$, at $37^{\circ} \mathrm{C}$ with $0.45 \mathrm{~g}$ PC $(95 \% \pm 5 \%)$ melted uniformly throughout.

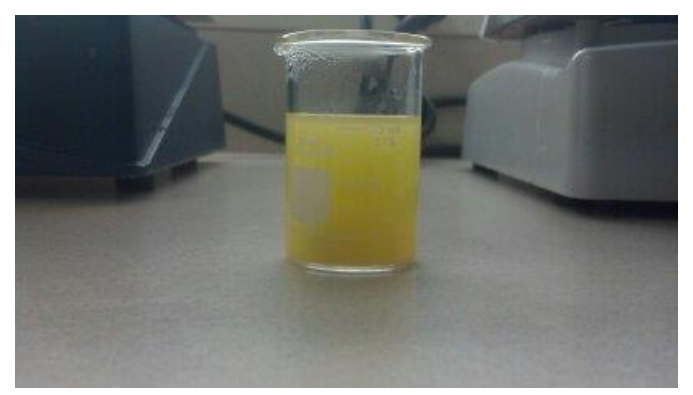

Figure 6: Control mixture from Figure 5 with $0.15 \mathrm{~g}$ folic acid added.

As a test, to a second, similarly prepared mixture at $\mathrm{pH} 7.4$ and $37^{\circ} \mathrm{C}, 0.45 \mathrm{~g}$ of highly solubilized dUMP $(95 \% \pm$ 5\%) was added (Figure 7), subsequent $\mathrm{pH}$ measured, and its contents compared to the first mixture (Figure 8). Two samples were procured from the second mixture for GC/MS analysis, one to test for the presence of thymidylate and one to test for the presence of PE.

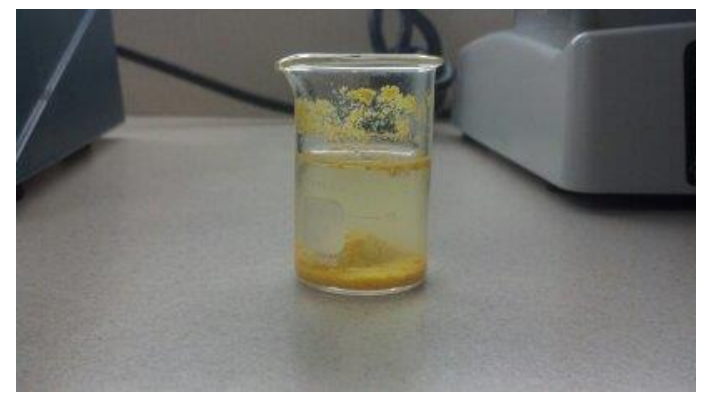

Figure 7: Test mixture, $\mathrm{pH} 6.2$, at $37^{\circ} \mathrm{C}$ with $0.45 \mathrm{~g}$ dUMP $(95 \% \pm 5 \%)$ added.

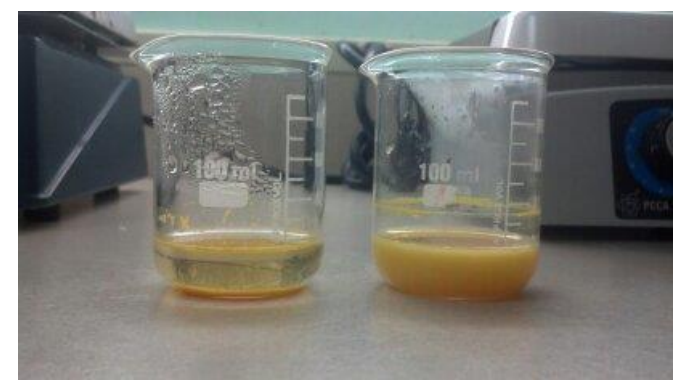

Figure 8: Comparison of test (left) and control (right) mixtures. 


\section{Results and Discussion}

At physiologic salinity, $\mathrm{pH}$, and temperature [13], no precipitation of any of the components of the control mixture was observed; furthermore, no precipitation was observed in this mixture as a function of $\mathrm{pH}$ within the stability range of a therapeutically relevant quantity of folic acid [14] and PC [15]. Precipitation, however, was observed in the test mixture, beginning immediately upon the addition of dUMP and reaching completion within 10 minutes after its addition. The $\mathrm{pH}$ of the test mixture was 6.2. Such precipitation, ruled out as a function of $\mathrm{pH}$, indicated an increase in hydrophobicity, as would be the case if hydrophilic dUMP were being converted into more hydrophobic thymidylate [16]. Also, the change in appearance of the mixture from opaque to translucent indicated the conversion of PC into PE [17]. GC/MS analysis confirmed the presence of both thymidylate (Figure 9) $(95 \% \pm 5 \%$ ) and PE (Figure 10) $(95 \% \pm 5 \%)$.

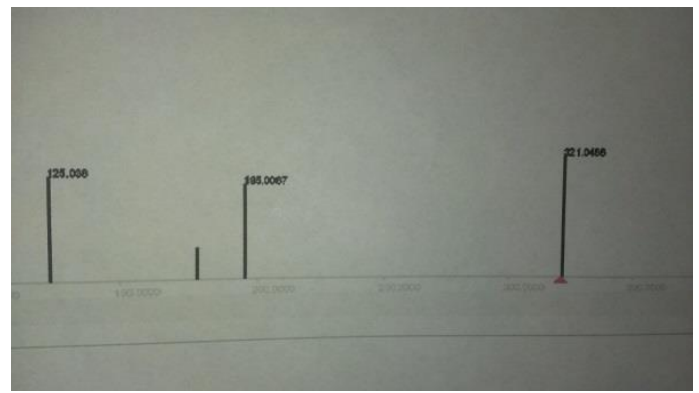

Figure 9: GC/MS of TMS-thymidylate $(95 \% \pm 5 \%)$ detected in test mixture. Note peak at $\mathrm{m} / \mathrm{z} 321.0488$.

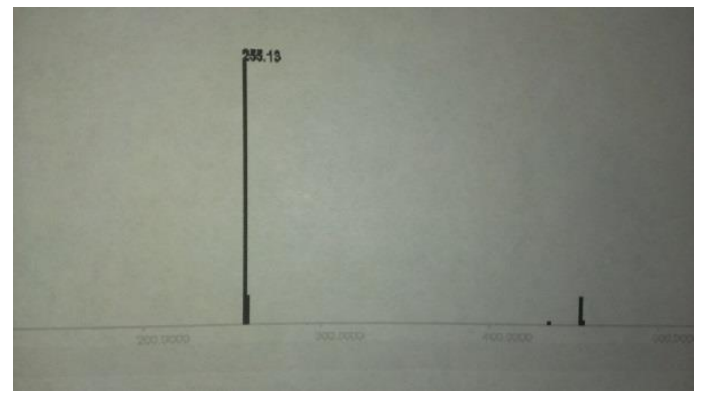

Figure 10: GC/MS of TMS-PE $(95 \% \pm 5 \%)$ detected in test mixture. Note peak at m/z 255.13.

The mechanism at work here appears to be extremely rapid and non-enzymatic in nature. It most likely involves successive de-methylation of PC by folic acid to form, first, a 5,10-methylenetetrahydrofolate intermediate and PE, with the former, then donating its methylene group to methylate dUMP into thymidylate, leaving a second, 7,8dihydrofolate intermediate, which then quickly oxidizes back to folic acid. Such a supposition is supported by observations of these two intermediates' formation by transient, acidic changes in $\mathrm{pH}$ by De Brouwer et al. [18]. This transient nature, however, along with the extremely rapid rate of reaction observed in this experiment, precludes their detection here, although its inferred presence seems to best account for the observed results.

Such a rapid, non-enzymatic mechanism would also account for the quick onset of action of folic acid therapy in the treatment of megaloblastic anemia, acting in an additional and complementary fashion with that in already 
elucidated enzymatic mechanisms. It also establishes folic acid, alongside SAM-e, as a powerful agent involved in the non-enzymatic methylation of endogenous nucleotides.

\section{Acknowledgements}

I thank the staff of The Wellness Pharmacy for the generous use of their facility and equipment. I also especially thank my loving family for their generous gift of time in the performance of these experiments and the writing of this article. This article is dedicated to the memory of Raymond Burnell Knepp (1942-2009), founder of The Wellness Pharmacy.

\section{References}

1. Sousa MM, Krokan HE, Slupphaug G. DNA-uracil and human pathology. Mol Aspects Med 28 (2007): 276-306.

2. NIH: National Institutes of Health. MedlinePlus: Megaloblastic anemia (2012).

3. Walletin L, Berlin R, Vikrot O. Studies on plasma lipid and phospholipid composition in pernicious anemia before and after specific treatment. Acta Med Scand 201 (1977): 161-165.

4. Horton HR, Moran LA, Ochs RS, et al. Principles of biochemistry ( $2^{\text {nd }}$ Edn.). Upper Saddle River, NJ: Prentice Hall (1996).

5. IPCS Inchem. Folic acid (1991).

6. Black GE, Abramson FP. Measuring DNA synthesis rates with stable isotopes. Anal Chem 75 (2003): 5663.

7. Barrows LR, Magee PN. Nonenzymatic methylation of DNA by S-adenosylmethionine in vitro. Carcinogenesis 3 (1982): 349-351.

8. ASHP guidelines on quality assurance for pharmacy-prepared sterile products. Drug distribution and control: Preparation and handling-guidelines (2010).

9. MassBank Record: PR100611. Thymidine-5'-monophosphate (2011).

10. MassBank Record: UT001356. Phosphatidylethanolamine (2011).

11. Black J. Microbiology. Prentice Hall (1993): 334.

12. Bolton S. Pharmaceutical statistics ( $3^{\text {rd }}$ Edn.). New York: Marcel Dekker (1997).

13. Seely R, Stephens T, Tate P. Anatomy and physiology ( $8^{\text {th }}$ Edn.). New York, NY: McGraw-Hill (2007).

14. De Brouwer V, Zhang GF, Storozhenko S, et al. pH stability of individual folates during critical sample preparation steps in prevision of the analysis of plant folates. Photochem Anal 18 (2007): 496-508.

15. Ho RJY, Schmetz M, Deamer DW. Nonenzymatic hydrolysis of phosphatidylcholine prepared as liposomes and mixed micelles. Lipids 22 (1987): 156-158.

16. Anandagopu P, Suhanya S, Jayaraj V, et al. Role of thymine in protein coding frames of mRNA sequences. Bioinformation 2 (2008): 304-307.

17. Avanti® Polar Lipids, Inc. MSDS: L- $\alpha$-phosphatidylethanolamine (E. coli) (2012). 
18. De Brouwer V, Zhang GF, Storozhenko S, et al. pH stability of individual folates during critical sample preparation steps in prevision of the analysis of plant folates. Photochem Anal 18 (2007): 496-508.

Citation: Bruce K. Kowiatek. An Additional, Complementary Mechanism of Action for Folic Acid in the Treatment of Megaloblastic Anemia. Journal of Biotechnology and Biomedicine 1 (2018): 021-027.

(c) (i)

This article is an open access article distributed under the terms and conditions of the

Creative Commons Attribution (CC-BY) license 4.0 